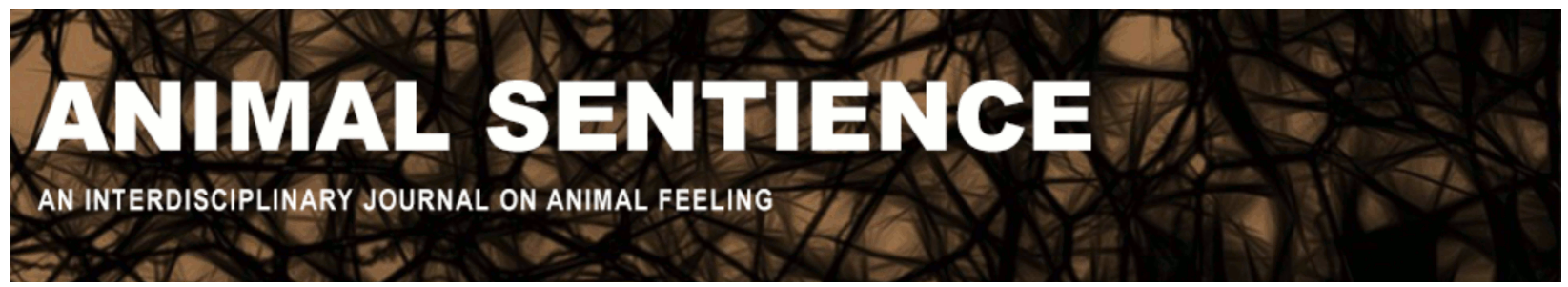

Marino, Lori and Merskin, Debra (2019) Intelligence, complexity, and individuality in sheep. Animal Sentience 25(1)

DOI: $10.51291 / 2377-7478.1374$

Date of submission: 2018-10-06

Date of acceptance: 2019-03-10 (c) 
Call for Commentary: Animal Sentience publishes Open Peer Commentary on all accepted target articles. Target articles are peer-reviewed. Commentaries are editorially reviewed. There are submitted commentaries as well as invited commentaries. Commentaries appear as soon as they have been reviewed, revised and accepted. Target article authors may respond to their commentaries individually or in a joint response to multiple commentaries.

INSTRUCTIONS FOR COMMENTATORS

\title{
Intelligence, complexity, and individuality in sheep
}

\author{
Lori Marino \\ Kimmela Center for Animal Advocacy, Utah \\ Debra Merskin \\ University of Oregon, Eugene
}

\begin{abstract}
Domestic sheep (Ovis aries) are among the earliest animals domesticated for human use. They are consumed worldwide as mutton, hogget, and lamb, kept as wool and milk producers, and used extensively in scientific research. The popular stereotype is that sheep are docile, passive, unintelligent, and timid, but a review of the research on their behavior, affect, cognition, and personality reveals that they are complex, individualistic, and social.
\end{abstract}

Keywords: sheep, lamb, Ovis aries, intelligence, cognition, personality, social, emotions

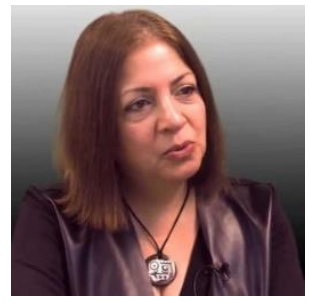

Lori Marino, neuroscientist, former faculty affiliate at the Emory Center for Ethics, President of the Whale Sanctuary Project, and Executive Director of the Kimmela Center for Animal Advocacy, has written over 130 publications on dolphin and whale brain evolution and anatomy; intelligence and self-awareness; and the effects of captivity on social mammals, including cetaceans, elephants and primates. She worked with the Nonhuman Rights Project and is featured in the films Blackfish and Unlocking The Cage. Website

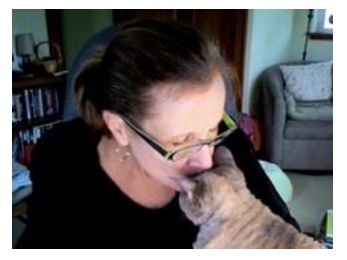

Debra Merskin is Professor of media studies in the School of Journalism and Communication at the University of Oregon. Her research focuses on how the media and popular press represent animals, resulting in species stereotypes, and how these portrayals affect the lived experiences of real animals. Her most recent book is Seeing Species: Re-Presentations of Animals in the Media \& Popular Culture (2018, Peter Lang). Website 
"Mary had a little lamb," "baa, baa, black sheep," Shari Lewis's Lamb Chop and the Serta mattress sheep are all examples of how sheep and lambs appear in popular consciousness. Images of happy lambs frolicking in fields are used on greeting cards, and as symbols of spring and Easter. Groups of sheep and lambs gladly grazing in wide open fields appear in many people's visions of where their sweaters and dinners come from. Collectively viewed as passive flocks, these gentle beings, because of their willingness to be led and handled, are stereotyped as unintelligent, simple-minded, and dependent. A review of the scientific literature paints a more complex picture of sheep as intelligent and highly social individuals.

\section{How We View Sheep}

In Christian theology, the worth and worthiness of all beings is arranged hierarchically, giving order and value to the universe. The Great Chain of Being (scala naturae), believed to be decreed by God, declares that "the cosmos radiates out from its source in a descending order of being" (Cobb 2005, p. 204). Thus, all beings have their proper place, and that place is preordained according to qualities possessed (or lacked) by groups in each category. Those on top have all the qualities of those below them, and then some. This hierarchical concept, derived from Greek philosophers such as Plato (Timaeus) and Aristotle (Historia Animalium), is also known as the "Ladder of Being" (or Great Chain of Being), depicting God or some deity on top, humans below, "higher animals" such as lions and primates next, and rocks (inanimate matter) at the bottom (Lovejoy 1936).

It is not surprising then that "higher animals" are thought to have the qualities that are most admired among humans. For example, lions are viewed as strong, powerful, and noble, and so are elephants. The next level down is composed of "useful animals" such as dogs, horses, and "docile" animals such as sheep. This hierarchical view has influenced thousands of years of treatment of nonhuman animals. In her study of the portrayal of animals in children's early natural history books, Ritvo (1985) notes:

The animal kingdom, with man in his divinely ordained position at its apex, offered a compelling metaphor for the hierarchical human social order, in which the animals represented subordinate human groups. Embodying the lower classes as sheep and cattle validated the authority and responsibility exercised by their social superiors. (p. 80)

This status is also reflected in language, particularly metaphor. For example, according to Goatly (2006):

HUMAN IS SHEEP: sheep - unthinking imitator or over obedient person; black sheep someone who brings shame to a family; mutton dressed as lamb - older woman trying to look young; bleat - complain; pull the wool over someone's eyes - deceive someone by giving false information ... a wolf in sheep's clothing - deceitful and cunning person. (p. 26)

Lakoff and Turner (1989) note that the scala naturae is "a contemporary unconscious cultural model indispensable to our understanding of ourselves, our world, and our language" (p. 167f). The model offers an explanation for the human propensity to determine the value of others on the basis of similarity to (or difference from) ourselves. Subordination, viewed as a "special bond with [humankind]," is prominent in evaluating the worth of animals: "Like the best human servants, the best animals understood their obligations and undertook them willingly; the worst were those that not only declined to serve but dared to challenge human 
supremacy." Sheep, who served as meat, milk, and wool, although viewed as "affectionate," were considered "stupid ... the equivalent of mindless drudges" (Ritvo 1985, p. 83).

Jones (1821) described sheep as "the most useful of the smaller quadrupeds" (p. 84) and "the most valuable" (p. 87) because they were sold for wool and milk and valued for their obedience. Yet they were not the most appreciated. Species "whose services to mankind are greater than those of the sheep, for ... they are employed ... as beasts of draught and burden" (p. 106), received higher regard.

Jones (1821) declared the domestic sheep "mild, innocent and gentle in its nature ... it seems conscious of its defenseless state, and looks to man for that protection, which it seeks in vain from its own species" although "the sheep delights in the society of its own species" (pp. 84-85). In sum, sheep have generally been considered useful working animals in literary cultural contexts, serving as linguistic metaphors for people who are viewed as blindly following en masse with no "mind of their own."

Contemporary attitudes towards animals continue to see sheep as valuable only as commodities. Mitchell (2012) identified a "discourse of production" (p. 491) that includes anthropocentrically loaded language that supports an ideology of domination and use. The "use names" we assign to animals we wish to consume or farm operate psychologically as moral justification for our practices. This instrumental attitude is supported in phrases such as "dual purpose sheep" (wool and lambs), "wool sheep," and "mutton breeds" (p. 495), as well as animals used for reproductive purposes ("stud rams") (p. 496).

Naming and labeling "is a possible contributory mechanism for facilitating people's "moral disengagement" (Mitchell 2012, p. 491) and thus facilitates industrialized farming of animals. In a three-part study of the personality characteristics attributed to nonhuman animals as metaphors (zoomorphs), Sommer and Sommer (2011) found that "most animal metaphors, when applied to human beings, are uncomplimentary, reinforcing the perceived distance between humans and non-human animal species" (p. 237). Sheep, in particular, were viewed in mostly uncomplimentary ways (59\%) - "Timid or bashful person, a simpleton. A sucker or poor player" (p. 244) - and as predominantly female (57\%). Furthermore, the use of animals is shaped by their "believed capabilities" (Nakajima, Arimitsu, \& Lattal 2002, p. 35), their perceived similarity to humans, the purpose of their use, and how much knowledge people have of how they are used.

American and Japanese students ranked sheep as 25th in intelligence out of 56 species (Nakajima et al. 2002, p. 199). Heleski, Mertig, and Zanella (2006) report a survey in which 446 veterinary college faculty (VCF) and 157 animal science faculty (ANS) (stakeholders involved in farm animal welfare) were more comfortable with current animal agriculture production systems for cows and sheep than for chickens. Women were more concerned with animal welfare than men. Obstacles to according greater attention to welfare included economics, lack of consumer willingness to pay, tradition, producer attitudes, and inad equate welfare science research. Many other studies of attitudes towards domestic sheep and their welfare report similar findings (Hills 1995; Knight \& Barnett 2008).

The views of sheep described above are consistent with their continued use as commodities and create the psychological need to downplay their intelligence and individuality. This is evident in the way sheep and lambs are raised under intensive industrial conditions for wool, milk, and meat, as well as their ubiquitous use in biomedical research. More than 10 million sheep are kept in factory farms. In the United States alone, 2-2.5 million individuals are killed each year (National Agricultural Statistics Service (NASS), Agricultural 
Statistics Board, and USDA 2018). Tail-docked at birth, they are allowed to live a maximum of six to eight months before being slaughtered for consumption.

Sheep and lamb hides are marketed worldwide and sold for hundreds of millions of dollars annually (World Statistical Compendium 2016). Sheep are also used extensively in biomedical research. According to Sheep 101, about 24,000 are used annually for a range of purposes, from the study of Huntington's disease and heart conditions to orthopedics, organ transplants, and genetic research (including cloning). These highly invasive and often terminal procedures are not limited or regulated in any significant way because farmed animals are not protected by the Animal Welfare Act.

This article will review the scientific literature with a special focus on identifying evidence for complex psychological capacities in sheep, particularly those shared with other animals we have little trouble perceiving as complex and intelligent. What follows is a brief summary of the evolution, phylogeny, and domestication of sheep; their sensory-perceptual capabilities; and their basic life history. The review will also try to identify aspects of sheep psychology that are not as thoroughly researched as they could be. As most research on sheep is driven by the commercial need to increase the efficiency of processing them as meat, there are likely to be many other more basic facets of sheep psychology that are not as well studied as those directly relevant to production.

\section{Evolution and Domestication}

Sheep are artiodactyls and members of the goat-antelope subfamily within the ruminant family Bovidae. They are grazing herbivores who prefer grass and short roughage. There are seven species of sheep; the best known is the domestic sheep, Ovis aries. We will focus on the domestic species, citing information on others when relevant.

Well over 1,200 breeds of domestic sheep are identified by the FAO (Food and Agriculture Organization of the United Nations 2016). Sheep were among the earliest animal species to be domesticated. $O$. aries is thought to be descended from $O$. orientalis, a species of wild sheep or mouflon ranging in Mesopotamia around 10,000 years ago (Dwyer 2009). Primary differences between wild and domesticated species of sheep include coat colors and patterns as well as size. An important difference in life history is that domestic sheep are neotenic compared with their wild counterparts. Life expectancy in domestic sheep is 12 years, but living as long as 20 years is not uncommon.

\section{Sensory Characteristics}

As prey animals, sheep have excellent vision and hearing. With visual fields of $270^{\circ}$ to $320^{\circ}$, sheep can see behind themselves without turning their heads (Sheep 101). Sheep also have an excellent sense of smell, and like all species of their genus, have scent glands in front of their eyes and between the digits on their feet. Taste is an important sense in sheep, establishing forage preferences, with sweet and sour plants preferred and bitter plants more commonly rejected. Males (rams) use their vomeronasal organ to sense the pheromones of females (ewes) and detect when they are in estrus. The female uses her vomeronasal organ for early recognition of her neonate lamb. There is also evidence that the primary olfactory system has specialized processing capacities for social cues in the brains of sheep (SanchezAndrade \& Kendrick 2009). Gestation is 145-150 days with single births or, sometimes, twins. Mothers form strong and exclusive bonds with their offspring. Lambs, under natural conditions, nurse for at least 6 months. Puberty is reached at 6-12 months. 


\section{Research Method}

To review the scientific and academic literature on sheep cognition and behavior, we first conducted searches on the Web of Science Core Collection using terms relevant to intelligence, cognition, and behavior. We followed up the searches with online Google-based direct searches through all of the major peer-reviewed journals (see Appendix, Table 1) using similar general terms as well as key terms from published papers (e.g., intelligence, cognition, behavior, learning, memory, personality, sociality, and self-awareness). We also used more specific search terms on the Web of Science within these broader categories when necessary. In addition, we used these same terms to search on ScienceDaily for relevant news items and peer-reviewed papers. We also conducted a complete search of the websites of the major authors in these fields for all of their relevant publications. Finally, we searched the reference section of each paper to find additional papers in additional journals (not listed in Table 1) to ensure that the overall search was comprehensive. We included books, book chapters, dissertations, and theses, as well as both empirical and review papers (which provided further description and interpretation of the empirical data). The basic comparative psychology literature as well as the applied literature were included. No date restrictions were placed on articles for inclusion, but priority was given to more recent papers. The reference section of the present paper shows the full breadth of the sources consulted. Our findings are divided into four broad categories in the four sections that follow: (5) Learning and Cognition, (6) Emotions, (7) Personality, and (8) Social Complexity.

\section{Learning and Cognition}

Cognition refers to the mechanisms by which an individual acquires, processes, stores, and acts upon information; it includes learning, memory, and decision-making (Shettleworth 2010). Intelligence refers to the rapidity, depth, and complexity of these mechanisms. There is always an interplay between "higher-level" cognitive processes and those considered to be more basic. Here we summarize what is currently known about cognition in sheep from a range of applied and basic studies.

5.1. Executive Functions. Executive functions are a set of cognitive processes that are involved in the monitoring and control of cognition, including the steps necessary to obtain goals. Executive functions include attention, cognitive inhibition, working memory, cognitive flexibility, and planning; they are based on prefrontal cortical function in humans and other mammals. Broom (2010) refers to executive awareness as the ability "to assess, deduce, and plan in relation to long-term intention" (p. 4). Diamond (2013) describes executive functions as making "mentally playing with ideas" (p.135) possible.

The evidence for sophisticated executive functions in primates, e.g., monkeys, is plentiful (Chudasama 2011; Moore et al. 2003, 2009). Executive function has been probed in adult sheep using three standard tests: visual discrimination learning, reversal learning, and attentional set-shifting. The discrimination tasks start from simple color discriminations to compound discriminations to intradimensional (color) shifts and reversal to extradimensional (shape) shifts and reversal. Sheep can perform not only the discrimination tasks and reversals but also the most complex tasks - the intra- and extra-dimensional setshifting tasks - parallelling the performance of humans and macaque monkeys (Morton \& Avanzo 2011). When the first rule shift occurs, the sheep show visible signs of anxiety and frustration. Attentional set-shifting is another challenging executive function in rule learning and reversal that sheep perform on a par with primates. 
5.2. Other Learning and Memory Abilities. Sheep have excellent general memory and learning abilities. Lambs show robust spatial memory (Nowack et al. 1994); they are able to learn basic tasks in as few as two trials (Bremmer, Baggins, \& Kilgour 1980). Other studies show that sheep perform well on visual discrimination tasks (Morris et al. 2010; Sugnaseelan et al. 2013); under some circumstances, however, auditory discriminations might be more difficult (Morris et al. 2010). In addition to object discrimination, sheep are competent at tasks requiring the learning of spatial navigation. Lee et al. (2006) showed that sheep are capable of learning and remembering a fairly complex maze. Testing memory and reversal learning using a modified Y-maze, Hunter et al. (2015) found that 18-and 40-week-old sheep could remember the maze for at least 22 weeks and that prior experience, not just age, correlated with maze performance. In a test of exclusion performance typically used with primates, sheep (and goats) had to choose between two cups, one of which was baited and covered. The sheep and goats were able to use direct information (the presence of food) to choose the correct location of the reward in the task, mastering the choice of baited cups upon having seen the cup previously baited (Nawroth et al. 2014).

Sheep can learn to discriminate between various flavors and generalize food knowledge on the basis of flavor (Launchbaugh 1994; Vilalba \& Provenza $2000 \mathrm{a}, \mathrm{b}$ ). They can also use their ability to discriminate tastes to self-medicate when they are ill (Vilalba et al. 2006). A number of studies show how sheep learn to discriminate between different edible plants using mental categorization. Sheep can categorize plants at the species level (Ginane \& Dumont 2010, 2011) and can classify food items at an even higher level (including at least two species), demonstrating that they are able to create a hierarchical representation of food categories, i.e., nested levels of perceptual information (Ginane \& Dumont 2010, 2011), in much the same way chimpanzees have been shown to classify flowers (Tanaka 2001).

5.3. Face Perception. Faces are complex configurations of various components, making face recognition a complicated mental task. The many aspects of face perception include identity, emotional expression, gaze, and attraction (Leopold \& Rhodes 2010). Like humans and other nonhuman primates such as macaque monkeys, sheep demonstrate neural, perceptual, and social specialization for faces. They prefer the faces of conspecifics to others and the faces of familiar sheep to unfamiliar conspecifics (da Costa et al. 2004). Using facial cues, sheep can also discriminate the breed and sex of other sheep (Kendrick et al. 1995). They exhibit a right hemisphere advantage for recognizing other sheep, with specialized face cells in the right temporal cortex (Kendrick \& Baldwin 1987; Peirce et al. 2000; Broad, Mimmack, \& Kendrick 2000; Peirce \& Kendrick 2002), but perhaps not for recognizing human faces (Peirce et al. 2001).

Sheep also show prodigious memory abilities. In a study of twenty adult sheep, Kendrick et al. (2001) showed they were capable of remembering fifty other individual sheep (by discriminating twenty-five pairs) for over two years. Studies using photographs of conspecifics show that sheep are able to discriminate among various individuals even when presented with photographs of the individuals at different ages and in different orientations (Ferreira et al. 2004). These findings demonstrate the robustness of facial recognition abilities in sheep and their ability to pick up invariants across a range of different presentations.

As highly social mammals, sheep are sensitive to emotional expressions and are able to distinguish between photographs of sheep with a calm facial expression and those with a startled expression (Elliker 2005). They can also recognize the fear in another sheep's 
expression (Tate et al. 2006). Discriminating among faces of conspecifics is an important component of social cognition, as it is the basis for the formation of relationships and social hierarchies of increasing social complexity.

Sheep also demonstrate sophisticated capabilities for discriminating between human faces (Davis et al. 1998; Peirce et al. 2001). In a recent study, eight adult sheep were trained to recognize the faces of four popular human celebrities in photographs on a computer screen. The sheep showed spatial orientation invariance, recognizing the four celebrities in tilted images. They were also able to distinguish a learned familiar face from an unfamiliar face, and could recognize a very familiar handler in photos. The authors concluded that sheep process faces holistically and have face recognition abilities on a par with those of humans and other primates (Knoll et al. 2017).

5.4. Responses to Mirrors. There are three general sequential stages of responses to mirrors: (1) exploratory and social behavior, (2) contingency-checking, and (3) self-directed behavior. There is convincing evidence that members of some taxa, including dolphins (Reiss \& Marino 2001), elephants (Plotnik et al. 2006), great apes (Anderson \& Gallup 2011), and magpies (Prior et al. 2008), can recognize themselves in mirrors, as they can use the mirror to investigate parts of their body (self-directed behavior). These findings are interpreted as evidence of a concept of the self comparable to that of humans at least in terms of a bodily self-concept. Other animals, such as monkeys (Itakura 1987), dogs (Howell et al. 2013), and pigs (Broom et al. 2009; but see Gieling et al. 2014), do not show self-directed behaviors using mirrors but can still use mirrors to find hidden food. This too is interpretable as showing some self-awareness, as in order to get the food, animals must understand the spatial relationship between the mirror image, their own body, and the hidden food.

All animals who eventually show self-directed behaviors pass through a contingencychecking phase in which the individuals seem to be testing the relationship between their body movements and those in the mirror image through such behaviors as repetitive head movements or popping in and out of the mirror frame. In a study of sheep, three different breeds were provided with a mirror and tested to see whether they could use it to find hidden food in a maze. All 29 sheep showed the early social/exploratory actions; some of them showed repetitive head movements and other behaviors indicative of contingency-checking. However, none of the sheep shown the mirror used it to find hidden food (McBride et al. 2015). Much more research is needed for a fuller picture of what sheep understand about mirrors. The fact that some sheep did show contingency-checking is noteworthy and suggests there could be more to their abilities than observed in this single study.

5.5. Summary of Findings on Sheep Cognition. Sheep show competence in many cognitive domains including memory and discrimination capacity. They excel especially in executive function and face perception, performing on par with some primates. These are both high-level abilities based on a number of different neocortical functions, the prefrontal cortex for executive function and the temporal cortex for face perception within and across species (Kendrick \& Baldwin 1987).

\section{Emotions}

Emotions are complex multifaceted phenomena sharing fuzzy boundaries with other aspects of psychology. Emotions include behavioral, neurophysiological, cognitive, and conscious subjective processes (Desire et al. 2002; Mendl \& Paul 2004). Emotions shape attention, decision-making, and memory and are in turn influenced by factors such as situational 
awareness and sensitivity to the experience of others. Emotions and cognition are often intimately tied together. For example, the memories can generate strong emotions and, in turn, modulate responses to various stimuli (Mendl, Burman, Parker, \& Paul 2009; Ohl, Arndt, \& van der Staay 2008; Paul, Harding, \& Mendl 2005). Affective neuroscience (Panksepp 2004) has played a key role in confirming that other animals experience emotions in ways similar to humans. This is particularly true in mammals despite the fact that there is information missing regarding taxonomic distribution (Bekoff 2005).

Studies of emotions in sheep, as in other animals, have tended to focus on just two easily measurable dimensions: valence (positive/negative or pleasant/unpleasant) and intensity (weak/strong), varying independently. There is also a growing literature on more complex emotions, such as cognitive bias, in sheep and other highly social mammals. Désiré et al. (2002) argue that our emphasis on the more basic unidimensional aspects of emotion in other animals arises more from our own assumptions about the nature of nonhuman emotions and limitations in measuring them rather than from any lack of complexity or subtlety in animal emotions.

The literature on emotions in sheep and other farmed animals is substantial and confirms that they experience a wide range of emotions and that some of those responses are quite complex. Basic emotional valence (positive/negative) studies indicate that sheep express their internal subjective states through multiple behavioral and physiological changes.

Ear posture appears to be an indicator of emotional state in sheep, as it is in cows. Proctor and Carder (2014) found that relaxed ear postures in cows, which include backward and hanging ear postures, are associated with gentle stroking. Reefman, Kaszàs, Wechsler, and Gygax (2009) showed in two separate experiments that ear postures in sheep are correlated with situations of inferred negative and positive emotional valence. During negative situations (e.g., when given unpalatable food), the number of ear-posture changes was the highest, and the proportion of forward and asymmetric ear postures was also high. In positive situations (e.g., when given enriched food), the ear posture remained more stable, with a high proportion of passive postures (ear hanging loosely). Reefman et al. noted that attention increased during negative but not positive emotional circumstances. They concluded that ear postures are a reliable measure of emotional states in sheep but that there are still complexities and nuances that need to be deciphered.

In another study, Reefman, Wechsler, and Gygax (2009) observed the reactions of 15 sheep in negative (separation from the group), intermediate (standing in a feeding area), and positive situations (being voluntarily groomed by a favorite human). Several ear postures, relative eye aperture, cardio-respiration, body surface humidity, and temperature were recorded continuously for up to 4 minutes in each condition. The groomed sheep had the fewest ear posture changes and the most relaxed ear postures; sheep in the negative condition had the most forward ear postures. Ear postures were also correlated with several physiological measures. Reefman et al. (2012) replicated these findings in a study of ear posture and other measures of ongoing emotional valence (mood), under different housing conditions over a longer term, with comparable results.

Boissy et al. (2011) also observed a correlation between different ear postures in sheep and situations that elicit emotional states, such as sudden events, unfamiliarity, uncontrollability, and negative contrast. Horizontal ear posture corresponded to a "neutral" emotional state; during unfamiliar and unpleasant, uncontrollable situations (interpreted as 
fear), the ears were positioned back; during negative but controllable situations (anger), ears were positioned straight up; and when surprised, ears were asymmetric (one up and one down). Ear posture, along with heart rate and other behavioral and physiological measures, confirms that lambs enjoy gentle stroking (Coulon et al. 2015).

The ear posture studies demonstrate that there are clear behavioral and physiological correlates of emotional states in sheep. They also tell us that there is a good deal of complexity to unpack, as it is important to clarify the various elements of emotion suggested by these findings.

Fear is probably the most commonly investigated emotion in domestic animals, including sheep. Fear is a reaction to perceived danger. Fearfulness has been tested and reliably measured in sheep for decades. Although there is wide individual variation in fear reactions in sheep based on personality, as a prey species, fear in sheep is typically expressed by behaviors such as highly focused visual and auditory vigilance, immobilization (a "frozen" posture), fleeing/attempts to escape, and defecation (Bouissou et al. 1996; Rohmeyer et al. 1992; Vierin et al. 2002).

In a study of how chronic stress affects fear reactions in the longer term, Destrez et al. (2013) exposed five-month-old lambs to six weeks of aversive and unpredictable events related to predation and negative handling. They found that, compared with a control group, these lambs showed more fearful reactions overall in a range of circumstances: approaching humans less often, having less contact with a novel object, and having more vocalizations. These findings suggest that the impact of uncontrollable aversive events is more complex than just provoking fearfulness at the time the events occur. They appear to affect ongoing mood and fearfulness, which, as described below, points to evidence for complex emotions in sheep.

In the cognitive modeling framework known as appraisal theory, emotions are viewed as the result of how an individual evaluates a triggering situation, following a sequence of checks, including the relevance of the situation (its suddenness, familiarity, predictability, and intrinsic pleasantness), its implications for the individual (including consistency with the individual's expectations), the potential for control, and both internal and external standards. Studies of appraisal theories have been applied to humans as well as other animals. A series of such studies in sheep by Vessier et al. (2009) confirmed that sheep evaluate events in their environment according to their suddenness, familiarity, predictability, and the consistency of these events with their own expectations and the control they have over the events - the same dimensions that shape human emotional responses, according to appraisal theory. Based on their responses to various situations that would trigger an emotional response in humans, the authors concluded that sheep seem able to experience a wide range of emotions, including fear, anger, rage, despair, boredom, disgust, and happiness (Vessier et al. 2009).

6.1. Complex Emotions. Sheep emotions are not limited to very basic feelings but can be complex. Complex emotional experiences are emotional responses which interact with other mental domains, such as cognition and sociality. There is evidence for complex emotions in sheep in four domains: cognitive (judgement) bias, emotional reactions to learning, emotional contagion, and social buffering.

6.1.1. Cognitive Bias. Cognitive bias, also known as negative (and positive) judgement bias, demonstrates the complex interaction between emotions and cognition. Negative judgement bias (sometimes referred to as pessimism) refers to negative responses to ambiguous stimuli after a negative emotional experience; positive bias (optimism) refers to 
the effects of positive emotional experiences on cognition. Cognitive bias is a phenomenon demonstrated in a wide range of animals including cows (Daros, Costa, von Keyserlingk, Hötzel, \& Weary 2014), pigs (Douglas, Bateson, Walsh, Bédué, \& Edwards 2012), bottlenose dolphins (Clegg, Rödel, \& Delfour 2017), capuchin monkeys (Pomerantz, Terkel, Suomi, \& Paukner 2012), and honeybees (Bateson, Desire, Gartside, \& Wright 2011).

The evidence for judgement bias in sheep is strong. Doyle et al. (2011) found that exposure to long-term unpredictable aversive events affected the motivation of sheep to approach a bucket associated with a discrimination task located in a neutral zone during a test. Destrez et al. (2013) found that exposure to chronically stressful situations led to more pessimistic judgement biases and learning deficits in lambs. Sheep demonstrate optimism and pessimism under the relevant circumstances, providing more evidence for a complex interplay between emotions and cognition. Sheep also showed a positive judgement bias in various cognitive tasks when they were restrained and then released, compared with sheep who were never restrained (Doyle et al. 2010; Sanger et al. 2011).

The ability to form expectations and then react to those that are violated is a complex cognitive capacity. An expectation is knowledge that one event precedes a second or leads to a particular outcome based on past experience. This definition assumes there is a mental representation of the outcome value, requiring complex cognitive processing, as it involves a comparison of actual characteristics of a situation with those that were expected. Grieveldinger et al. (2011) designed a study to determine whether lambs are able to form expectations and whether they respond emotionally when those expectations are violated. When an expected reward for completing a task was less than expected, the lambs responded emotionally (with increased cardiac responses and locomotion), particularly when they had previously experienced an increased reward. These findings demonstrate that not only can sheep form expectations and have feelings about whether those expectations are met, but also that they can follow a fairly complex set of events leading to an outcome. The authors interpreted the emotions of the lambs after a let-down of their expectations as frustration and despair.

6.1.2. Emotional Reactions to Learning. Emotional reactions to learning refer to the emotional effects of improving on a task apart from the reactions to a reward itself: positive emotions and excitement when realizing one is controlling a situation and getting closer to a goal. Individuals may become excited because they can control the delivery of a reward. It has been argued that this kind of complex emotional experience rests upon some level of selfawareness such as self-referral or self-agency (Hagen \& Broom 2004). Hagen and Broom (2004) studied the emotional responses of heifers during a period when they were learning a task. Heifers were put into a small pen with a gate through which a food bowl could be seen 20 meters away. If the heifer put her nose into a hole in the wall and broke a light beam, the gate opened. When the heifers learned how to open the gate, they showed behavioural excitement in the form of jumping and bucking, and an elevated heart-rate response at the moment of learning.

Matched control heifers that received the same reward after spending the same time in the pen did not show this response and neither did heifers that had previously learned the task and immediately opened the gate upon entering the test pen. The authors speculated that the increased arousal in the experimental group was a direct result of the experimental animals' reaching the point of realizing that their performance on the task had improved: an 
emotional reaction to a sense of self-efficacy in this situation. These findings have implications for the question of self-awareness in cows.

Similar results were obtained by Broom and Barone (in preparation) in a study on learning in sheep. The authors suggest that the sheep may have been aware of their own success in solving a problem. They call this phenomenon the "eureka effect" (Broom, personal communication). Although much more work needs to be done on this effect in sheep, they may indeed, like cows, be reacting emotionally to knowing that they have successfully learned a task.

6.1.3. Emotional Contagion. Emotions can influence more than one individual in a group through a process known as emotional contagion. Emotional contagion occurs when an individual experience matches the emotional response of others; many authors consider it a foundation for empathy (De Waal 2003, 2008; Preston \& De Waal 2002; Singer 2006). Empathy can be defined as having an emotional state similar to that of another as a result of the accurate perception of the other's situation (Hatfield et al. 1993; Preston \& de Waal 2002). There is both a cognitive and an emotional component to empathy. De Waal (2008) suggests that emotional contagion forms the basis of sympathetic concern (which involves some perspective-taking) and can lead to empathy-based altruism. Emotional contagion has been demonstrated in many socially complex taxa such as dogs (Joly-Mascheroni, Senju, \& Shepherd 2008), wolves (Romero, Ito, Saito, \& Hasegawa 2014), great apes (Anderson, Myowa-Yamakoshi, \& Matsuzawa 2004; Palagi, Norscia, \& Demuru 2014), pigs (Reimert, Bolhuis, Kemp, \& Rodenburg 2013, 2014), and cows (Boissy et al. 1998).

One example of emotional contagion is contagious yawning, in which yawning is triggered by another individual's yawning. Contagious yawning has been demonstrated in humans and many other mammals, such as dogs; wolves; chimpanzees (Campbell \& deWaal 2011); rats (Moyaho et al. 2014); and one avian species, budgerigars (Miller et al. 2012). Sheep also show contagious yawning. In a study of twelve adult sheep, it was found that when visually paired together, if one sheep yawned, the other did so within one minute over $11 \%$ of the time; they did not do this when they were shielded from one another. Sheep also showed synchronized rumination under the same circumstances (Yonezawa et al. 2017).

Another way sheep demonstrate empathy is through the responses of mothers to their offspring. Hild et al. (2011) showed that ewes paid more attention to their lambs when the lambs showed they were in pain (e.g., from tail-docking). Interestingly, the ewes did not pay more attention when the lambs were stressed. These results indicate that the ewes either distinguished between pain and psychological distress or could not detect psychological distress in this way.

6.1.4. Social Buffering. Social buffering occurs when an individual reacts less negatively or intensely to stresses and fear-inducing situations when in the presence of conspecifics (Kikusui, 2006). The conspecifics act as a social buffer to lessen the emotional stress. Social buffering exemplifies the important emotional role the social group plays for many animals, including sheep. Social buffering has been demonstrated in humans (Thorsteinsson et al. 1998), macaques (Gilbert \& Baker 2011), chickens (Edgar et al. 2015), and cows (Boissy \& Le Neindre 1990; Grignard et al. 2000).

Not surprisingly, the evidence for social buffering in sheep is substantial. Da Costa et al. (2004) reported that when sheep experienced social isolation, the sight of pictures of familiar sheep faces (but not goats or geometric shapes) significantly reduced behavioural (activity and protest vocalizations), autonomic (heart rate), and endocrine (cortisol and 
adrenaline) indices of stress. Very similar results were found by Vandenheede et al. (1994) and Bousseau et al. (1996): the sheep were also able to distinguish photographs of sheep of their own breed from those of another breed, showing less fear toward their own breed.

6.2. Mother-Offspring Relationship. Ewes and their lambs form strong emotional bonds rapidly following birth (Nowack et al. 2000). Ewes stay close to their young lambs and encourage following behaviour at the earliest stage (Lent 1974), creating stable motheroffspring bonds within a mobile flock (Hersher et al. 1963). Lambs also establish a clear preference for their mothers rather than other adult females during the early rearing period (Arnold \& Dudzinski 1975; Nowak et al. 1989; Hernández et al. 2009). Mothers communicate with their lambs using low-pitched bleats similar to mother-child vocalizations in many other species (Dwyer et al. 1998). As young as 12 hours old, sheep can identify their mothers through sight and sound (Poindron, Nowak, Lévy, Porter, \& Schaal 1993).

The intensity of the ewe-lamb bond changes throughout the lactation period, as the lamb gains gradual independence from the mother (Weary et al. 2008). Natural weaning begins at around six months but may continue until almost a year (Grubb 1974). Some studies show that, if given the opportunity, mothers and their offspring tend to associate with each other even after weaning (Hinch et al. 1990; Rowell 1991). Under intensive factory farming conditions, ewes and their lambs are separated at as early as one month and typically between 2 and 4 months (Napolitano 2008). This practice causes emotional distress for the lamb and the mother. During the first days after separation, lambs attempt to reunite with their mothers and show a distressed emotional response by vocalizing and pacing (Freitasde-Melo et al. 2017; see also Poindron et al. 2007, for a review). These behaviors are exclusive to the loss of the mother.

When mothers are separated from their lambs during pre-weaning, they show strong anxious behaviors such as high-pitched vocalizations, elimination, and increased locomotion (Poindron et al. 1994). Napolitano et al. (2008) reviewed evidence that artificial weaning and early separation from the mother have negative psychological effects on lambs through different phases of their development. The mother-offspring bond in sheep is hence very strong early on and vulnerable to negative effects if the natural weaning process is interrupted or not allowed to unfold gradually.

6.3. Play. Play behavior can be a good indicator of positive emotional states in other animals (Held \& Spinka 2011). Play is related to curiosity, mood, exploration, and innovation; it forms the basis for complex object-related and social abilities (Bateson, Bateson, \& Martin 2013) in humans and other animals. Play is also a general expression of a positive mood. Mammals and nonmammals engage in play (Bekoff \& Byers 1998; Burghardt 2005, 2015). Many farmed animals, such as pigs (Horback 2014) and cows (Reinhardt et al. 1978), exhibit a range of complex object and social play behaviors. Sheep are no exception.

After about the first week of life, lambs form play groups (Morgan \& Arnold 1974), and sex differences become apparent. Males tend to play more aggressively, headbutting and mounting each other (Chapagain et al. 2014; Orgeuer et al. 1984); females tend to engage in more locomotor play, such as gamboling and frolicking. Both perform exaggerated and exuberant body movements like "bucking," spinning, and whirling around (Spinka et al. 2001). All these behaviors indicate that sheep, like most other animals, express positive emotions in interactions with their environment and one another.

6.4. Summary of Findings on Sheep Emotions. Sheep have emotions that range across the spectrum and combine with cognition in complex ways. They show evidence of 
cognitive bias, emotional reactions to learning, emotional contagion (which may be a simple form of empathy), and social buffering. In the social realm, strong bonds between mothers and their offspring can last for several months.

\section{Personality}

Personality is a set of traits that differ across individuals and are consistent over time: "those characteristics of individuals that describe and account for temporally stable patterns of affect, cognition, and behavior" (Gosling 2008, p. 986). The individuality of personality traits has important implications for how we regard and treat other animals. Individual differences in personality contradict the view that other animals are one-dimensional, interchangeable units within a group, population, or species (as we often think of sheep and other herding animals such as cows). Personality also interacts with cognition and emotion, shaping behavior and performance on a wide range of tasks (Carere \& Locurto 2011).

Personality traits are ubiquitous in the animal kingdom among mammals and nonmammals (Vonk, Weiss, \& Kuczaj 2017). Personality structure in nonhuman animals maps on to the Five-Factor Model representing broad dimensions of human personality (Gosling 2008; Gosling \& John 1999). These include the dimensions of openness, conscientiousness, extroversion, agreeableness, and neuroticism (e.g., McCrae \& Costa 2008). Although some authors refer instead to "behavioral syndromes" or "temperament" in other animals (Reale, Reader, Sol, McDougall, \& Dingemanse 2007), there is little distinction between these phenomena and personalities as observed and documented (Gosling 2008).

In sheep, too, there is evidence of individual personality. One of the dimensions that has been identified is shyness-boldness. Tests of shyness and boldness - based on risktaking, reactions to novelty, and levels of exploration, and often correlated with patterns of foraging, spatial distribution, and responses to other groups - provide evidence of this personality dimension in sheep (Murphy et al. 1994; Sibbald et al. 2009). The shy-bold continuum is now recognized as a fundamental dimension of behavioural variation in humans and nonhuman animals alike (Wilson et al. 1994)

Michelena, Sibbald, Erhard, and McLeod (2008) studied the role of individual personality under conditions of increased feeding competition. They first identified individuals as bold or shy based on their willingness to leave the group in an indoor exploration test. The individuals with bold personalities were more likely to split into subgroups during grazing experiments on patchy grass, suggesting that individual personality can influence spatial organization. Michelena et al. (2009) reported that individual differences in boldness and the proportion of bold to shy individuals could affect the foraging decisions of the entire group, with bold individuals acting as leaders.

Another personality dimension is gregariousness. Sheep are a highly social species, but individuals differ in gregariousness, which is correlated with behavioural synchronization in ewes. Gregariousness can be measured as the time an individual spends in close proximity to others. Behavioral synchronization, a fundamental property of social cohesion, is the simultaneous occurrence of the same behavior in two or more individuals. Hauschildt and Gerken (2015) found that the proportion of gregarious individuals in a group predicts behavioral synchronization, showing that the mixture of individual personality traits in a group can influence social cohesion.

Other personality traits in sheep include reactivity, activity level, and calmness/anxiety. There is evidence, however, that these labels (and their operational 
definitions) may be variants of the same trait (Bickell et al. 2009; Murphy et al. 1998) and many authors use them interchangeably. (For example, Beausoleil et al. (2012) tested sheep characterized as more versus less active in various situations but interpreted the results in terms of calmness, reactivity, and anxiety as if they were all a single dimension.)

Many of these tests involve placing sheep unrestrained but isolated from the social group in an unfamiliar setting (such as an open field) in the presence of an unfamiliar human. The researchers then measure activity level, escape speed, avoidance, and vocalizations. The other option is testing in a restrained situation in a small crate or box (as a proxy for handling), measuring levels of agitation, struggling, and vocalization. The correlation between these two types of assessments - unrestrained and restrained - is moderate and mixed (Dodd et al. 2012). One disadvantage of interpreting behavior in unrestrained tests like the novel arena is that high levels of locomotion are ambiguous - interpretable as either exploration or anxiety. These two interpretations could represent different personality dimensions: either boldness or anxiety.

Personality traits in ewes also have an impact on maternal behavior and the survival of the lamb. Using principle component analysis, Dwyer and Lawrence (2000) found that the maternal style of ewes could be consistently characterized by two axes: warmth/maternal care versus maternal rejection. Maternal protectiveness is not on the opposite end of a linear scale to maternal rejection, and ewes can show high levels of rejecting behaviours without showing a reduction in other positive caring behaviors such as grooming. Although the frequency of maternal rejection diminished with maternal experience, these two dimensions remained distinct across time. The authors suggest that both may be related to the trait of emotionality in sheep. Poindran et al. (2007) identified two dimensions of maternal style in ewes that heavily influence maternal attachment: maternal responsiveness and maternal selectivity. These findings raise the question of whether maternal style itself is a single personality trait or a combination of traits.

7.1. Summary of Findings on Sheep Personality. There is abundant evidence of personality traits in sheep, in particular, shyness/boldness and gregariousness. More research is needed on other potential dimensions and complexities of sheep personality, in particular, the more general personality concepts such as reactivity/anxiety.

\section{Social Complexity}

The social complexity of species has conventionally been defined by the number of individuals and the number and kinds of differentiated roles and relationships among them (Bergman \& Beehner 2015). Differentiated relationships are those that require recognizing and responding to differences across individuals (e.g., dominance roles, kinship, and other more complex multidimensional differences). Seyfarth and Cheney (2015) defined social cognition as knowledge about one's conspecifics. A general definition of social complexity arguably includes the number of differentiated relationships, the degree of knowledge about conspecifics, and the knowledge of one's own and other animals' social interactions and relationships. There is abundant evidence of a positive correlation between various highlevel cognitive capacities and measures of social complexity in species as diverse as domestic pigs (see Marino \& Colvin 2015, for a review), dogs (see Bensky et al. 2013, for a review), primates (e.g., Dunbar 1998), dolphins and whales (Fox, Muthukrishna, \& Schultz 2017; Whitehead \& Rendell 2015), and birds (Burish et al. 2004). 
Sheep tend to form groups based on affiliative bonds. Boissy and Dumont (2002) reported that ewes placed near familiar companions grazed longer, vocalized less, and were less vigilant than ewes surrounded by unfamiliar conspecifics. Social organization in sheep can also be quite variable, with bigger differences between populations than genera (Shackleton \& Shank 1984). Sheep are sexually dimorphic; dominance hierarchies commonly develop among males, but are weak or nonexistent in females (Shackleton \& Shank 1984). Fighting is closely related to horn and head structures, with horns being used for fighting and as indicators of social rank (Shackleton \& Shank 1984).

Like other farmed animals, sheep may display more behavioral plasticity than previously thought (Estevez, Andersen, \& Nævdal 2007) if provided the opportunity outside factory farming conditions. There is evidence that personality traits of individual sheep influence group movement and distribution (Hauschildt \& Gerken 2015), as noted above, and that personality is an important factor in social behavior (Doyle et al. 2016).

Michelena, Sibbald, Erhard, and McLeod (2008) showed that boldness and shyness in individual sheep influence the tendency for groups to split into subgroups. Social bonds are so important to sheep that they prefer to stay with their social group rather than forage at a distance for highly prized food (Dumont \& Boissy 2000). Special bonds also predict order during group movement in a pasture. In a study of nineteen one-year-old ewe-lambs without kinship ties, those with preferential bonds were significantly more likely to follow one another during group movements (Ramseyer, Boissy, Thierry, \& Dumont 2009). Social cohesion - the number of times an individual is seen in proximity to another - was also measured. Ewe lambs with low social cohesion, that is, a low number of partners with whom they shared frequent affinitive interactions, were more often the first individuals to move away from the social group in search of more food, showing less attachment to the group. Moreover, those individuals with higher cohesion indices were more often in front of the group once the group started moving (Ramseyer, Boissy, Thierry, \& Dumont 2009). These results show that the morphology of a social group and its movements are shaped by the personalities of the individuals within the group.

Social cohesion is also modulated by activity synchrony and social affinity. Michelena, Gautrais, Gérard, Bon, and Deneubourg (2008) tested the effects of activity, group size, and sex composition on the cohesion of mixed-sex and single-sex Merino groups. The sheep were more aggregated than would be expected in a random spatial distribution for all groups and sizes. Social cohesion was shaped by the activity level of the group. Individuals were closest together when resting and farthest apart when only part of the group was active. Groups that were all active maintained close inter-individual distances but were less close when resting.

Given that social bonds are so important in the lives of sheep, it is not surprising that there is strong evidence that being forced to live in isolation causes distress behaviors. For example, Lauber, Nash, Gatt, and Hemsworth (2012) observed 96 individually housed castrated Merino sheep using 15-minute sampling over a 10-hour period for two consecutive days over three weeks. Seventy-one percent of the sheep displayed one or more behaviors that are abnormal for sheep, such as pacing and chewing and nosing pen fixtures, for more than $10 \%$ of the day. The prevalence and incidence of these behaviors were high, especially compared to sheep who grazed outdoors and were housed with other sheep.

8.1. Summary of Findings on Sociality in Sheep. Sheep groupings are not homogeneous but hierarchical, dynamic, complex relationships shaped by individual personalities and many other factors. 


\section{Conclusions}

We have identified a variety of findings from the scientific literature on learning and cognition, emotions, personality, and social complexity showing that contrary to popular views and representations of sheep as unintelligent and lacking in individuality or autonomy, they have several complex capacities including:

1. a number of prefrontal lobe executive functions considered on par with primates;

2. considerable capacity to distinguish and identify faces of other sheep as well as humans;

3. a range of simple to complex emotions, including judgement bias and forms of emotional contagion;

4. distinct personalities;

5. strong mother-offspring bonds and relationships that shape social groupings beyond food availability and distribution.

Our review contradicts historical perceptions of sheep that fuel and sustain contemporary media, popular culture, and farming practices. As discussed earlier, Christian and other theologies situate sheep in the contemporary consciousness as obedient, passive, and uniform; this view has negative consequences for sheep. Representing farmed animals through language as objects, not subjects, of farming, research, and hide-harvesting practices, serves to distance humans psychologically from other animals. It is our hope that this comprehensive analysis of scientific literature will serve as the foundation for reconsidering the use of sheep as commodities in modern agricultural production and in invasive research, and will promote learning more about sheep using noninvasive research in more natural and noncoercive settings such as sanctuaries.

Acknowledgement: We would like to thank Kristin Allen for her exceptional contribution in identifying and compiling some of the research findings in this article.

\section{References}

Anderson, J. R., \& Gallup, G. G., Jr. (2011). Which primates recognize themselves in mirrors? PLoS Biology, 9(3), e1001024.

Anderson, M. C., Myowa-Yamakoshi, M., \& Matsuzawa, T. (2004). Contagious yawning in chimpanzees. Proceedings of the Royal Society Biological Sciences, 27(Suppl. 6), S468S470.

Arnold, G. W., \& Dudzinski, M. L. (1978). Maternal behavior. In G. W. Arnold \& M. L. Dudinski (Eds.), Ethology of free-ranging animals (pp. 137-165). Amsterdam: Elsevier.

Bateson, M., Desire, S., Gartside, S. E., \& Wright, G. A. (2011). Agitated honeybees exhibit pessimistic cognitive biases. Current Biology, 21(12), 1070-1073.

Bateson, P. P. G., Bateson, P., \& Martin, P. (2013). Play, playfulness, creativity and innovation. Cambridge, UK: Cambridge University Press.

Beausoleil, N. J., Blache, D., Stafford, K. J., Mellor, D. J., \& Noble, A. D. (2012). Selection for temperament in sheep: Domain-general and context-specific traits. Applied Animal Behaviour Science, 139(1-2), 74-85. 
Bekoff, M. (2005). The question of animal emotions: An ethological perspective. In F. D. McMillan (Ed)., Mental health and well-being in animals (pp. 15-28). Ames, IA: Blackwell.

Bekoff, M., \& Byers, J. A. (Eds.). (1998). Animal play: Evolutionary, comparative and ecological perspectives. Cambridge, UK: Cambridge University Press.

Bensky, M.K., Gosling, S. D., \& Sinn, D. L. (2013). The world from a dog's point of view: A review and synthesis of dog cognition research. Advances in the Study of Behavior, 45, 209-406.

Bergman, T. J., \& Beehner, J. C. (2015). Measuring social complexity. Animal Behaviour, 103, 203-209.

Bickell, S. L., Nowak, R., Poindron, P., Sebe, F., Chadwick, A., Ferguson, D., \& Blache, D. (2009). Temperament does not affect the overall establishment of mutual preference between the mother and her young in sheep measured in a choice test. Developmental Psychobiology, 51(5), 429-438.

Boissy, A., \& Dumont, B. (2002). Interactions between social and feeding motivations on the grazing behaviour of herbivores: Sheep more easily split into subgroups with familiar peers. Applied Animal Behaviour Science, 79(3), 233-245.

Boissy, A., \& Le Neindre, P. (1990). Social influences on the reactivity of heifers: Implications for learning abilities in operant conditioning. Applied Animal Behaviour Science, 25(1-2), 149-165.

Boissy, A., Aubert, A., Désiré, L., Greiveldinger, L., Delval, E., \& Veissier, I. (2011). Cognitive sciences to relate ear postures to emotions in sheep. Animal Welfare, 20(1), 47.

Boissy, A., Terlouw, C., \& Le Neindre, P. (1998). Presence of cues from stressed conspecifics increases reactivity to aversive events in cattle: Evidence for the existence of alarm substances in urine. Physiology and Behavior, 63, 489-495.

Bouissou, M. F., Porter, R. H., Boyle, L., \& Ferreira, G. (1996). Influence of a conspecific image of own vs. different breed on fear reactions of ewes. Behavioural Processes, 38(1), 37-44.

Bremner, K. J., Braggins, J. B., \& Kilgour, R. (1980). Training sheep as “leaders" in abattoirs and farm sheep yards. Proceedings of the New Zealand Society of Animal Production, 40, 111-116.

Broad, K. D., Mimmack, M. L, \& Kendrick, K. M. (2000). Is right hemisphere specialization for face discrimination specific to humans? European Journal of Neuroscience, 12(2), 7310741.

Broom, D. (2010). Cognitive ability and awareness in domestic animals and decisions about obligations to animals. Applied Animal Behavior Science, 126(1/2), 1-11.

Broom, D., Sena, H., \& Moynihan, K. L. (2009). Pigs learn what a mirror image represents and use it to obtain information. Animal Behaviour, 78, 1037-1041.

Burghardt, G. (2015). Play in fishes, frogs and reptiles. Current Biology, 25(1), R9-R10.

Burghardt, G. M. (2005). The genesis of animal play: Testing the limits. Cambridge, MA: MIT Press.

Burish, M. J., Kueh, H. Y., \& Wang, S. H. (2004). Brain architecture and social complexity in modern and ancient birds. Brain, Behaviour, and Evolution, 63(2), 107-124.

Campbell, M. W., \& de Waal, F. B. (2011). Ingroup-outgroup bias in contagious yawning by chimpanzees supports link to empathy. PLoS One, 6e, 18283.

Carere, C., \& Locurto, C. (2011). Interaction between animal personality and animal cognition. Current Zoology, 57, 491-498. 
Chapagain, D., Uvnäs-Moberg, K., \& Lidfors, L. M. (2014). Investigating the motivation to play in lambs. Applied Animal Behaviour Science, 160, 64-74.

Chudasama, Y. (2011). Animal models of prefrontal-executive function. Behavioral Neuroscience, 125(3), 327.

Clegg, I. L., Rödel, H. G., \& Delfour, F. (2017). Bottlenose dolphins engaging in more social affiliative behaviour judge ambiguous cues more optimistically. Behavioural Brain Research, 322, 115-122.

Cobb, K. (2005). The Blackwell guide to theology and popular culture. Malden, MA: Blackwell.

Coulon, M., Nowak, R., Peyrat, J., Chandèze, H., Boissy, A., \& Boivin, X. (2015). Do lambs perceive regular human stroking as pleasant? Behavior and heart rate variability analyses. PLoS ONE, 10(2), e0118617

da Costa, A. P., Leigh A. E., Man, M.-S., \& Kendrick, K. M. (2004). Face pictures reduce behavioural, autonomic, endocrine and neural indices of stress and fear in sheep. Proceedings of the Royal Society B: Biological Sciences, 271(1552), 2077-2084.

Daros, R. R., Costa, J. H., von Keyserlingk, M. A., Hötzel, M. J., \& Weary, D. M. (2014). Separation from the dam causes negative judgement bias in dairy calves. PLoS One, 9(5), e98429.

Davis, H., Norris, C., \& Taylor, A. (1998). Whether ewe know me or not: The discrimination of individual humans by sheep. Behavioural Processes, 43(1), 27-32.

De Waal, F. B. M. (2003). On the possibility of animal empathy. In A. S. R. Manstead, N. Frijda, \& A. Fisch (Eds.), Feelings and emotions: The Amsterdam symposium (pp. 377-399). Cambridge, UK: Cambridge University Press.

De Waal, F. B. M. (2008). Putting the altruism back into altruism: The evolution of empathy. Annual Review of Psychology, 59, 279-300.

Désiré, L., Boissy, A., \& Veissier, I. (2002). Emotions in farm animals: A new approach to animal welfare in applied ethology. Behavioural Processes, 60(2), 165-180.

Destrez, A., Deiss, V., Leterrier, C., Boivin, X., \& Boissy, A. (2013). Long-term exposure to unpredictable and uncontrollable aversive events alters fearfulness in sheep. Animal, $7(3), 476-484$.

Diamond, A. (2013). Executive functions. Annual Review of Psychology, 64, 135-168.

Dodd, C. L., Pitchford, W. S., Edwards, J. E. H., \& Hazel, S. J. (2012). Measures of behavioural reactivity and their relationships with production traits in sheep: A review. Applied Animal Behaviour Science, 140(1/2), 1-15.

Douglas, C., Bateson, M., Walsh, C., Bédué, A., \& Edwards, S. A. (2012). Environmental enrichment induces optimistic cognitive biases in pigs. Applied Animal Behaviour Science, 139(1/2), 65-73.

Doyle, R. E., Broster, J. C., Barnes, K., \& Browne, W. J. (2016). Temperament, age, and weather predict social interaction in the sheep flock. Behavioural Processes, 131, 53-58.

Doyle, R. E., Fisher, A. D., Hinch, G. N., Boissy, A., \& Lee, C. (2010). Release from restraint generates a positive judgement bias in sheep. Applied Animal Behaviour Science, 122(1), 28-34.

Doyle, R. E., Lee, C., Deiss, V., Fisher, A. D., Hinch, G. N., \& Boissy, A. (2011). Measuring judgement bias and emotional reactivity in sheep following long-term exposure to unpredictable and aversive events. Physiology \& Behavior, 102(5), 503-510.

Dumont, B., \& Boissy, A. (2000). Grazing behaviour of sheep in a situation of conflict between feeding and social motivations. Behavioural Processes, 49(3), 131-138. 
Dunbar, R. (1998). The social brain hypothesis. Brain, 9(10), 178-190.

Dwyer, C. (2009). The behaviour of sheep and goats. In P. Jensen (Ed.), The ethology of domestic animals: An introductory text (pp. 161-176). 2nd ed. Wallingford, Oxfordshire, UK: CAB International.

Dwyer, C. M., \& Lawrence, A. B. (2000). Maternal behaviour in domestic sheep (Ovis aries): Constancy and change with maternal experience. Behaviour, 137(10), 1391-1413.

Dwyer, C. M., McLean, K. A., Deans, L. A., Chirnside, J., Calvert, S. K., \& Lawrence, A. B. (1998). Vocalisations between mother and young in sheep: Effects of breed and maternal experience. Applied Animal Behaviour Science, 58(1-2), 105-119.

Edgar, J., Held, S., Paul, E., Pettersson, I., Price, R. I. A., \& Nicol, C. (2015). Social buffering in a bird. Animal Behaviour, 105, 11-19.

Elliker, K. R. (2005). Social cognition and its implications for the welfare of sheep. Ph.D. Thesis. Cambridge, UK: University of Cambridge.

Estevez, I., Andersen, I. L., \& Nævdal, E. (2007). Group size, density and social dynamics in farm animals. Applied Animal Behaviour Science, 103(3-4), 185-204.

Ferreira, G., Keller, M., Saint-Dizier, H., Perrin, G., \& Lévy, F. (2004). Transfer between views of conspecific faces at different ages or in different orientations by sheep. Behavioural Processes, 67(3), 491-499.

Food and Agriculture Organization of the United Nations. (2016). World statistical compendium for raw hides and skins, leather and leather footwear 1999-2015.

Fox, K. C. R, Muthukrishna, M., \& Shultz, S. (2017). The social and cultural roots of whale and dolphin brains. Nature, 1(11), 1699.

Freitas-de-Melo, A., Ungerfeld, R., Hötzel, M. J., Orihuela, A., \& Pérez-Clariget, R. (2017). Low pasture allowance until late gestation in ewes: Behavioural and physiological changes in ewes and lambs from lambing to weaning. Animal, 11(2), 285-294.

Gieling, E. T., Mijdam, E., van der Staay, F. J., \& Nordquist, R. E. (2014). Lack of mirror use by pigs to locate food. Applied Animal Behavior Science, 154, 22-29.

Gilbert, M. H., \& Baker, K. C. (2011). Social buffering in adult male rhesus macaques (Macaca mulatta): Effects of stressful events in single vs. pair housing. Journal of Medical Primatology, 40(2), 71-78.

Ginane, C., \& Dumont, B. (2010). Do grazing sheep use species-based categorization to select their diet? Behavioural Processes, 84(2), 622-624.

Ginane, C., \& Dumont, B. (2011). Do sheep (Ovis aries) categorize plant species according to botanical family? Animal Cognition, 14(3), 369-376.

Goatly, A. (2006). Human, animals, and metaphors. Society \& Animals, 14(1), 15-37.

Gosling, S. (2008). Personality in nonhuman animals. Social and Personality Psychology Compass, 2, 985-1001.

Gosling, S., \& John, O. P. (1999). Personality dimensions in nonhuman animals. Current Directions in Psychological Science, 8, 69-75.

Greiveldinger, L., Veissier, I., \& Boissy, A. (2011). The ability of lambs to form expectations and the emotional consequences of a discrepancy from their expectations.

Psychoneuroendocrinology, 36(6), 806-815.

Grignard, L., Boissy, A., Boivin, X., Garel, J. P., \& Le Neindre, P. (2000). The social environment influences the behavioral responses of beef cattle to handling. Applied Animal Behaviour Science, 68, 1-11. 
Grubb, P. (1974). Social organization of Soay sheep and the behaviour of ewes and lambs. In P. A. Jewell, C. Milner, \& J. Morton Boyd (Eds.), Island survivors: The ecology of the Soay sheep of St Kilda (pp. 131-159). London: Athlone Press.

Hagen, K., \& Broom, D. M. (2004). Emotional reactions to learning in cattle. Applied Animal Behaviour Science, 85, 203-213.

Hatfield, E., Cacioppo, J., \& Rapson, R. L. (1993). Emotional contagion. Current Directions in Psychological Science, 2, 96-99.

Hauschildt, V., \& Gerken, M. (2015). Individual gregariousness predicts behavioural synchronization in a foraging herbivore, the sheep (Ovis aries). Behavioural Processes, 113, 110-112.

Held, S. D., \& Špinka, M. (2011). Animal play and animal welfare. Animal Behaviour, 81(5), 891-899.

Heleski, C. R., Mertig, A. G., \& Zanella, A. J. (2006). Stakeholder attitudes toward farm animal welfare. Anthrozoös, 19(4), 290-307.

Hernandez, C. E., Harding, J. E., Oliver, M. H., Bloomfield, F. H., Held, S. D., \& Matthews, L. R. (2009). Effects of litter size, sex and periconceptional ewe nutrition on side preference and cognitive flexibility in the offspring. Behavioural Brain Research, 204(1), 82-87.

Hersher, L., Richmond, J. B., \& Moore, A. U. (1963). Maternal behavior in sheep and goats. In H. L. Rheingold (Ed.), Maternal behavior in mammals (pp. 203-232). New York: Wiley.

Hild, S., Clark, C. C., Dwyer, C. M., Murrell, J. C., Mendl, M., \& Zanella, A. J. (2011). Ewes are more attentive to their offspring experiencing pain but not stress. Applied Animal Behaviour Science, 132(3-4), 114-120.

Hills, A. M. (1995). Empathy and belief in the mental experience of animals. Anthrozoös, $8(3), 132-142$.

Hinch, G. N., Lynch, J. J., Elwin, R. L., \& Green, G. C. (1990). Long-term associations between Merino ewes and their offspring. Applied Animal Behaviour Science, 27(1), 93-103.

Horback, K. (2014). Nosing around: Play in pigs. Animal Behavior and Cognition, 1(2), 186196.

Howell, T. J., Toukhsati, S., Conduit, R., \& Bennett, P. (2013). Do dogs use a mirror to find hidden food? Journal of Veterinary Behavior, 8(6), 425-430.

Hunter, D. S., Hazel, S. J., Kind, K. L., Liu, H., Marini, D., Owens, J. A., Pitcher, J. B., \& Gatford, K. L. (2015). Do I turn left or right? Effects of sex, age, experience and exit route on maze test performance in sheep. Physiology and Behavior, 139, 244-253

Itakura, S. (1987). Mirror-guided behavior in Japanese macaques (Macaca fuscata fuscata). Primates, 28, 149-161.

Joly-Mascheroni, R. M., Senju, A., \& Shepherd, A. (2008). Dogs catch human yawns. Biology Letters, 4, 446-448.

Jones, J. (1821). The natural history of domestic animals: Containing an account of their habits and instincts, and of the services they render to man. New York: Charles Scribner's Sons.

Kendrick, K. M., \& Baldwin, B. A. (1987). Cells in temporal cortex of conscious sheep can respond preferentially to the sight of faces. Science, 236(4800), 448-450.

Kendrick, K. M., Atkins, K., Hinton, M. R., Broad, K. D., Fabre-Nys, C., \& Keverne, E. B. (1995). Facia and vocal discrimination in sheep. Animal Behavior, 49, 1665-1676.

Kendrick, K. M., da Costa, A. P., Leigh, A. E., Hinton, M. R., \& Peirce, J. W. (2001). Sheep don't forget a face. Nature, 414(6860), 165-166. 
Kendrick, K. M., Da Costa, A. P., Broad, K. D., Ohkura, S., Guevara, R., Levy, F., \& Kaverne, E. B. (1997). Neural control of maternal behaviour and olfactory recognition of offspring. Brain Research Bulletin, 44, 383-395.

Kikusui, T., Winslow, J. T., \& Mori, Y. (2006). Social buffering: Relief from stress and anxiety. Philosophical Transactions of the Royal Society of London B: Biological Sciences, 361(1476), 2215-2228.

Knight, S., \& Barnett, L. (2008). Justifying attitudes toward animal use: A qualitative study of people's views and beliefs. Anthrozoös, 21(1), 31-42.

Knolle, F., Goncalves, R. P., \& Morton, A. J. (2017). Sheep recognize familiar and unfamiliar human faces from two-dimensional images. Royal Society Open Science, 4, 171228.

Lakoff, G., \& Turner, M. (1989). More than cool reason: A field guide to poetic metaphor. Chicago, IL: University of Chicago Press.

Lauber, M., Nash, J. A., Gatt, A., \& Hemsworth, P. H. (2012). Prevalence and incidence of abnormal behaviours in individually housed sheep. Animals, 2(1), 27-37.

Launchbaugh, K. L., \& Provenza, F. D. (1994). The effect of flavor concentration and toxin dose on the formation and generalization of flavor aversions in lambs. Journal of Animal Science, 72, 10-13.

Lee, C., Colegate, S., \& Fisher, A. D. (2006). Development of a maze test and its application to assess spatial learning and memory in Merino sheep. Applied Animal Behaviour Science, 96(1-2), 43-51.

Lent, P. C. (1974). Mother-infant relationships in ungulates. In V. Geist \& F. Walther (Eds.), The behaviour of ungulates and its relationship to management (pp. 14-55). IUCN Publications, 24(1). Morges, Switzerland.

Leopold, D. A., \& Rhodes, G. (2010). A comparative view of face perception. Journal of Comparative Psychology, 124(3), 233.

Lovejoy, A. 0. (1936). The great chain of being: A study of the history of an idea. Cambridge, MA: Harvard University Press.

Marino, L., \& Colvin, T. (2015). Thinking pigs: A comparative review of cognition, emotion, and personality in Sus domesticus. International Journal of Comparative Psychology, 28, 122.

McBride, S. D., Perentos, N., \& Morton, A. J. (2015). Understanding the concept of a reflective surface: Can sheep improve navigational ability through the use of a mirror? Animal Cognition, 18, 361-371

McCrae, R. R., \& Costa, P. T. (2008). The five-factor theory of personality. In O. P. John, R. W. Robins, \& L. A. Pervin (Eds.), Handbook of personality (pp. 159-181). New York: Guildford Press.

Mendl, M., \& Paul, E. S. (2004). Consciousness, emotion and animal welfare: Insights from cognitive science. Animal Welfare, 13(1), 17-25.

Mendl, M., Burman, O. H., Parker, R. M., \& Paul, E. S. (2009). Cognitive bias as an indicator of animal emotion and welfare: Emerging evidence and underlying mechanisms. Applied Animal Behaviour Science, 118(3-4), 161-181.

Michelena, P., Gautrais, J., Gérard, J. F., Bon, R., \& Deneubourg, J. L. (2008). Social cohesion in groups of sheep: Effect of activity level, sex composition and group size. Applied Animal Behaviour Science, 112(1-2), 81-93. 
Michelena, P., Jeanson, R., Deneubourg, J. L., \& Sibbald, A. M. (2009). Personality and collective decision-making in foraging herbivores. Proceedings of the Royal Society of London B: Biological Sciences, rspb20091926.

Michelena, P., Sibbald, A. M., Erhard, H. W., \& McLeod, J. E. (2008). Effects of group size and personality on social foraging: The distribution of sheep across patches. Behavioral Ecology, 20(1), 145-152.

Miller, M. L., Gallup, A. C., Vogel, A. R., Vicario, S. M., \& Clark, A. B. (2012). Evidence for contagious behaviors in budgerigars (Melliosittacus undulates): An observational study of yawning and stretching. Behavioral Processes, 89, 264-270.

Mitchell, L. (2012). Nonhumans and the ideology of purpose. Anthrozoös, 25(4), 491-502.

Moore, T. L., Killiany, R. J., Herndon, J. G., Rosene, D. L., \& Moss. M. B. (2003). Impairment in abstraction and set shifting in aged rhesus monkeys. Neurobiological Aging, 24, 125134.

Moore, T. L., Schettler, S. P., Killiany, R. J., Rosene, D. L., \& Moss, M. B. (2009). Effects on executive function following damage to the prefrontal cortex in the rhesus monkey (Macaca mulatta). Behavioural Neuroscience, 123, 231-241.

Morgan, P. D., \& Arnold, G. W. (1974). Behavioural relationships between Merino ewes and lambs during the four weeks after birth. Animal Production, 19(2), 169-176.

Morris, J. E., Fisher, A. D., Doyle, R. E., \& Bush, R. D. (2010). Determination of sheep learning responses to a directional audio cue. Journal of Applied Animal Welfare Science, 13(4), 347-360.

Morton, A. J., \& Avanzo, L. (2011). Executive decision-making in the domestic sheep. PLoS ONE, 6(1), e15752.

Moyaho, A., Rivas-Zamudio, X., Ugarte A., Eguivar, J. R., \& Valencia, J. (2014). Smell facilitates auditory contagious yawning in stranger rats. Animal Cognition, 18, 279-290.

Murphy, P. M., Lindsay, D. R., \& Le Neindre, P. (1998). Temperament of Merino ewes influences maternal behaviour and survival of lambs. Proceedings of the 32nd Congress of the International Society for Applied Ethology, 32, 131.

Murphy, P. M., Purvis, I. W., Lindsay, D. R., Le Neindre, P., Orgeur, P., \& Poindron, P. (1994). Measures of temperament are highly repeatable in Merino sheep and some are related to maternal behaviour. Procedings of the Austrailian Society of Animal Production, 20, 247-254.

Nakajima, S., Arimitsu, K., \& Lattal, K. M. (2002) Estimation of animal intelligence by university students in Japan and the United States. Anthrozoös, 15(3), 194-205.

Napolitano, F., De Rosa, G., \& Sevi, A. (2008). Welfare implications of artificial rearing and early weaning in sheep. Applied Animal Behaviour Science, 110(1/2), 58-72.

National Agricultural Statistics Service (NASS), Agricultural Statistics Board, and USDA. (2018). (January 1). Sheep and goats.

Nawroth C., von Borell, E., \& Langbein, J. (2014). Exclusion performance in dwarf goats (Capra aegagrus hircus) and sheep (Ovis orientalis aries). PLoS ONE, 9(4), e93534.

Nowak, R. (1994). Mother location by newborn lambs in repetitive testing: Influence of first successful reunion. Applied Animal Behavior Science, 41, 75-86.

Nowak, R., Poindron, P., \& Putu, I. G. (1989). Development of mother discrimination by single and multiple newborn lambs. Developmental Psychobiology, 22(8), 833-845. 
Nowak, R., Porter, R. H., Lévy, F., Orgeur, P., \& Schaal, B. (2000). Role of mother-young interactions in the survival of offspring in domestic mammals. Reviews of Reproduction, 5(3), 153-163.

Ohl, F., Arndt, S. S., \& van der Staay, F. J. (2008). Pathological anxiety in animals. The Veterinary Journal, 175(1), 18-26.

Orgeur, P., \& Signoret, J. P. (1984). Sexual play and its functional significance in the domestic sheep (Ovis ovis L.). Physiology and Behavior, 33, 111-118.

Palagi, E., Norscia, I., \& Demuru, E. (2014). Yawn contagion in humans and bonobos: Emotional affinity matters more than species. PeerJ, 2, e519.

Panksepp, J. (2004). Affective neuroscience: The foundations of human and animal emotions. Oxford University Press.

Paul, E. S., Harding, E. J., \& Mendl, M. (2005). Measuring emotional processes in animals: The utility of a cognitive approach. Neuroscience \& Biobehavioral Reviews, 29(3), 469-491.

Peirce, J. W., \& Kendrick, K. M. (2002). Functional asymmetry in sheep temporal cortex. Neuroreport, 13(16), 2395-2399.

Peirce, J. W., Leigh, A., \& Kendrick, K. (2000) Configural coding, familiarity and the right hemisphere advantage for face recognition in sheep. Neuropsychologia, 38(4), 475-483.

Peirce, J. W., Leigh, A., daCosta, A. P., \& Kendrick, K. M. (2001). Human face recognition in sheep: Lack of configurational coding and right hemisphere advantage. Behavioural Processes, 55(1), 13-26.

Plotnik, J. M., de Waal, F. B. M., \& Reiss, D. (2006). Self-recognition in an Asian elephant. Proceedings of the National Academic of Sciences, 103, 17052-17057.

Poindron, P., Lévy, F., \& Keller, M. (2007). Maternal responsiveness and maternal selectivity in domestic sheep and goats: The two facets of maternal attachment. Developmental Psychobiology, 49(1), 54-70.

Poindron, P., Nowak, R., Lévy, F., Porter, R. H., \& Schaal, B. (1993) Development of exclusive bonding in sheep and goats. Oxford Reviews of Reproductive Biology, 15, 311-364.

Pomerantz, O., Terkel, J., Suomi, S. J., \& Paukner, A. (2012). Stereotypic head twirls, but not pacing, are related to a 'pessimistic'-like judgment bias among captive tufted capuchins (Cebus apella). Animal Cognition, 15(4), 689-698.

Preston, S. D., \& de Waal, F. B. M. (2002). Empathy: Its ultimate and proximate bases. Behavioural Brain Science, 25, 1-2.

Prior, H., Schwarz, A., \& Gunturkun, O. (2008). Mirror-induced behavior in the magpie (Pica pica): Evidence of self-recognition. PLoS Biology, 6, 1642-1650.

Proctor, H. S., \& Carder, G. (2014). Can ear postures reliably measure the positive emotional state of cows? Applied Animal Behaviour Science, 161, 20-27.

Ramseyer, A., Boissy, A., Thierry, B., \& Dumont, B. (2009). Individual and social determinants of spontaneous group movements in cattle and sheep. Animal, 3(9), 13191326.

Reale, D., Reader, S. M., Sol, D., McDougall, P. T., \& Dingemanse, N. J. (2007). Integrating animal temperament within ecology and evolution. Biological Reviews of the Cambridge Philosophical Society, 82(2), 291-318.

Reefmann, N., Kaszàs, F. B., Wechsler, B., \& Gygax, L. (2009). Ear and tail postures as indicators of emotional valence in sheep. Applied Animal Behaviour Science, 118(3/4), 199-207. 
Reefmann, N., Muehlemann, T., Wechsler, B., \& Gygax, L. (2012). Housing induced mood modulates reactions to emotional stimuli in sheep. Applied Animal Behaviour Science, 136(2/4), 146-155.

Reefmann, N., Wechsler, B., \& Gygax, L. (2009). Behavioural and physiological assessment of positive and negative emotion in sheep. Animal Behaviour, 78(3), 651-659.

Reimert, I., Bolhuis, J. E., Kemp, B., \& Rodenburg, T. B. (2014). Emotions on the loose: Emotional contagion and the role of oxytocin in pigs. Animal Cognition, 18, 517-532.

Reinhardt, V., Mutiso, F. M., \& Reinhardt, A. (1978). Social behavior and social relationships between female and male prepubertal bovine calves (Bos indicus). Applied Animal Ethology, 4, 43-54.

Reiss, D., \& Marino, L. (2001). Self-recognition in the bottlenose dolphin: A case of cognitive convergence. Proceedings of the National Academy of Sciences USA, 98, 5937-5942.

Ritvo, H. (1985). Learning from animals: Natural history for children in the eighteenth and nineteenth centuries. Children's Literature, 13, 72-93.

Romero, T., Ito, M., Saito, A., \& Hasegawa, T. (2014). Social modulation of contagious yawning in wolves. PLoS One, 9, e105963.

Romeyer, A., \& Bouissou, M. F. (1992). Assessment of fear reactions in domestic sheep, and influence of breed and rearing conditions. Applied Animal Behaviour Science, 34(1), 93119.

Rowell, T. E. (1991). Till death us do part: Long-lasting bonds between ewes and their daughters. Animal Behaviour, 42, 681-682.

Sanchez-Andrade, G., \& Kendrick, K. M. (2009). The main olfactory system and social learning in mammals. Behavioural Brain Research, 200(2), 323-335.

Sanger, M. E., Doyle, R. E., Hinch, G. N., \& Lee, C. (2011). Sheep exhibit a positive judgement bias and stress-induced hyperthermia following shearing. Applied Animal Behaviour Science, 131(3-4), 94-103.

Seyfarth, R., \& Cheney, D. (2015). How sociality shapes the brain, behaviour and cognition. Animal Behaviour, 103, 187-190.

Shackleton, D. M., \& Shank, C. C. (1984). A review of the social behavior of feral and wild sheep and goats 1. Journal of Animal Science, 58(2), 500-509.

Sheep 101. Science of the lambs.

Shettleworth, S. J. (2010). Cognition, evolution and behavior. 2nd ed. New York: Oxford.

Sibbald, A. M., Erhard, H. W., McLeod, J. E., \& Hooper, R. J. (2009). Individual personality and the spatial distribution of groups of grazing animals: An example with sheep. Behavioural Proceedings, 82, 319-326.

Singer, T. (2006). The neuronal basis and ontogeny of empathy and mind reading: Review of literature and implications for future research. Neuroscience \& Biobehavioral Review, 30, 855-863.

Sommer, R., \& Sommer, B. A. (2011). Zoomorphy: Animal metaphors for human personality. Anthrozoös, 24(3), 237-248.

Spinka, M., Newberry, R. C., \& Bekoff, M. (2001). Mammalian play: Training for the unexpected. Quarterly Review of Biology, 76(2), 141-168.

Sugnaseelan, S., Prescott, N. B., Broom, D. M., Wathes, C. M., \& Phillips, C. J. (2013). Visual discrimination learning and spatial acuity in sheep. Applied Animal Behaviour Science, 147(1-2), 104-111. 
Tanaka, M. (2001). Discrimination and categorization of photographs of natural objects by chimpanzees (Pan troglodytes). Animal Cognition, 4, 201-211.

Tate, A. J., Fischer, H., Leigh, A. E., \& Kendrick, K. M. (2006). Behavioural and neurophysiological evidence for face identity and face emotion processing in animals. Philosophical Transactions of the Royal Society of London B: Biological Sciences, 361, 2155-2172.

Thorsteinsson, E. B., James, J. E., \& Gregg, M. E. (1998). Effects of video-relayed social support on hemodynamic reactivity and salivary cortisol during laboratory-based behavioral challenge. Health Psychology, 17(5), 436.

Vandenheede, M., \& Bouissou, M. F. (1994). Fear reactions of ewes to photographic images. Behavioural Processes, 32(1), 17-28.

Veissier, I., Boissy, A., Désiré, L., \& Greiveldinger, L. (2009). Animals' emotions: Studies in sheep using appraisal theories. Animal Welfare, 18(4), 347-354

Viérin, M., \& Bouissou, M. F. (2002). Influence of maternal experience on fear reactions in ewes. Applied Animal Behaviour Science, 75(4), 307-315.

Villalba, J. J., \& Provenza, F. D. (2000a). Roles of novelty, generalization, and post-ingestive feedback in the recognition of foods by lambs. Journal of Animal Science, 78, 3060-3069.

Villalba, J. J., \& Provenza, F. D. (2000b). Roles of flavor and reward intensities in acquisition and generalization of food preferences: Do strong plant signals always deter herbivory? Journal of Chemical Ecology, 26, 1911-1922.

Villalba, J. J., Provenza, F. D., \& Shaw, R. (2006). Sheep self-medicate when challenged with illness-inducing foods. Animal Behaviour, 71(5), 1131-1139.

Vonk, J., Weiss, A., \& Kuczaj, S. (Eds.). (2017). Personality in nonhuman animals. NY: Springer.

Weary, D. M., Jasper, J., \& Hötzel, M. J. (2008). Understanding weaning distress. Applied Animal Behavioural Science, 110, 24-41.

Whitehead, H., \& Rendell, L. (2015). The cultural lives of whales and dolphins. Chicago, IL: University of Chicago Press.

Wilson, D. S., Clark, A. B., Coleman, K., \& Dearstyne, T. (1994). Shyness and boldness in humans and other animals. Trends in Ecology \& Evolution, 9, 442-446.

Yonezawa, T., Sato, K., Uchida, M., Matsuki, N., \& Yamazaki, A. (2017). Presence of contagious yawning in sheep. Animal Science Journal, 88(1), 195-200.

Call for Commentary: Animal Sentience publishes Open Peer Commentary on all accepted target articles. Target articles are peer-reviewed. Commentaries are editorially reviewed. There are submitted commentaries as well as invited commentaries. Commentaries appear as soon as they have been reviewed, revised and accepted. Target article authors may respond to their commentaries individually or in a joint response to multiple commentaries.

INSTRUCTIONS FOR COMMENTATORS 


\title{
APPENDIX
}

Table 1.

\section{Major Refereed Journals Searched}

\author{
Animal Behaviour \\ Animal Behavior and Cognition \\ Animal Cognition \\ Animal Welfare \\ Applied Animal Behaviour Science \\ Behaviour \\ Behavioural Brain Research \\ Behavioural Processes \\ Brain, Behaviour and Evolution \\ Current Biology \\ Domestic Animal Endocrinology \\ Hormones and Behavior \\ International Journal of Comparative Psychology \\ Journal of Animal Science \\ Journal of Applied Animal Welfare Science \\ Journal of Comparative Psychology \\ Journal of Mammalogy \\ Nature \\ Physiology and Behavior \\ PLoS Biology \\ PLoS One \\ Science
}

